\title{
Seismic investigation on the cathedral of Syracuse by finite elements and by a specific rigid body and spring model
}

\author{
S. Casolo \& C. A. Sanjust \\ Dipartimento di Ingegneria Strutturale, Politecnico di Milano, Italy
}

\begin{abstract}
The seismic behaviour of the cathedral of Syracuse, Sicily, is investigated by means of two complementary numerical analyses. The monument was built during the 5th century BC, as the Athena temple of Syracuse, and afterward repeatedly modified, mainly by Byzantines and next by Normans, to adapt it to the Christian worship. The complex geometry and the damaged conditions of some masonry elements make the modelling of this monument a challenging task. Moreover, the seismic investigation of this building needs non-linear dynamical analyses that can be practically performed only by adopting models with a limited number of degrees of freedom. Thus, we combined a 3-D finite element linear elastic analysis of the whole building with a 2-D non-linear full dynamical analysis of the transverse section of the building which adopted a specific rigid body and spring model, RBSM. Then, making reference to this latter model, the seismic performance of the building was investigated with reference to a real ground motion recording and to artificial accelerograms whose intensity is compatible with the seismic events that corresponds to return periods of 140 and 475 years. Keywords: dynamics, macro-scale, masonry, rigid element, spring model, texture.
\end{abstract}

\section{Introduction}

Monumental buildings have specific architectonic parts, such as large façades, pillars, slender columns, arches and vaults that often suffer damage and mechanical degradation even when subjected to moderate earthquakes. In these cases, in order to obtain a reliable estimation of the seismic risk, it is desirable to perform full dynamic analyses that permit to describe the effective dissipation of the seismic 
energy into the structure $[1,2]$. It is well known that modelling the non-linear mechanical behaviour of masonry monuments by means of three-dimensional (3-D) models requires a great amount of computational resources that are not commonly available. Luckily, it is often effective to subdivide these monuments into architectonic macro-elements - e.g. the façade, the triumphal arch, the bell tower, the apse - since the seismic response of these single parts tends to be dominated by recurrent damage mechanisms, and the mechanical interrelation between contiguous parts is limited [3, 4]. Moreover, when performing complete dynamic analyses it is often preferable to adopt a two-dimensional (2-D) model [5], even if the definition of a simplified model often requires a process of tuning in order to approximate as well as possible the features of the specific kinematics of interest. Thus, in the present study we integrated two complementary numerical approaches in order to obtain a comprehensive knowledge of seismic response of the cathedral:

1. a global 3-D finite element model of the whole monument, whose application was limited to the linear elastic analysis;

2. a 2-D rigid element model of the transverse section of the cathedral, aimed at investigating the non-linear seismic response by dynamical analysis.

In the second approach, the masonry material was modelled at the macroscale as an assemblage of unit cells made by rigid mass elements and springs. A unit cell conceptually is a sort of heuristic molecule - i.e. the smallest mechanism which retains the essential mechanical properties of the original composite masonry material. The present rigid elements are quadrilateral, and are connected at each side by three elastic-plastic line springs whose characteristics are defined by a specific procedure of identification, with the objective of transferring the main mechanical effects of the masonry internal texture to the macroscale model $[6,7]$. The material response under cyclic loading was modelled by means of a phenomenological approach based on the experimental tests available in the technical literature $[8,9]$.

\section{The cathedral of Syracuse}

\subsection{The history}

Syracuse was founded by early Sicilian populations around the 9th century BC, but only with the Greek colonization of southern Italy - in the 8th century BC the city became the most important settlement of eastern Sicily. In the 5th century Carthaginians invaded the island and were defeated at Battle of Himera by Gelon, tyrant of Syracuse; to celebrate this victory, a new temple dedicated to Athena, the Athenaion, was built on the highest side of the small island of Ortygia. This temple has nowadays become the Catholic cathedral of Syracuse. Originally the building was a peripteral hexastyle temple with fourteen Doric columns per side. Each column measured $8.71 \mathrm{~m}$ in height and $1.92 \mathrm{~m}$ in diameter in the lower side, and the basement measured about $22 \times 55 \mathrm{~m}$. The whole temple was built with local limestone and it did not undergo any major change during the centuries of the 

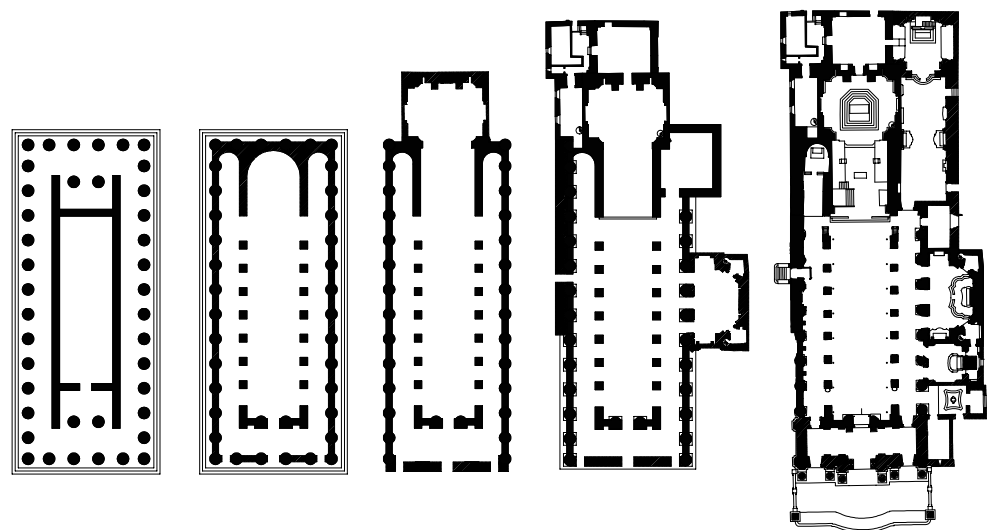

Figure 1: Evolution of the cathedral of Syracuse, from left to right: the plan of the original temple (5th century $\mathrm{BC}$ ), the cathedral in the Byzantine period (6th-7th century AC), in the Norman period (11th-12th century AC) and the plan of the present building (right).

Roman domination. After the fall of Roman Empire in the 5th century AC, Sicily and southern Italy became part of the Byzantine Empire. In this period the temple was adapted to the Christian worship, with the building of stone walls between the columns of the peristyle, and the opening of eight arches in the side walls of the cella; three apses were also build on the east side of the naos, transforming the temple in a Christian church with a nave and two aisles (fig. 1). During the brief Arab occupation of Sicily the cathedral probably fall into disuse, until the reconquest of the island by the Normans in the 11th century. The most important changes in the structure of the monument date back to this period, when the central nave (the former cella of the temple) was raised to the actual height, requiring also the building of a new façade (fig. 2). In the same period the central apse was enlarged and a bell tower was built. Other changes to the structure of the cathedral occurred in 16th and 17th centuries, due to the strong earthquakes which stroke Syracuse in 1542 and 1693. In particular, the collapse of the Norman façade and of the bell tower caused serious damages to the whole structure. The present exterior aspect of the monument belongs to that period.

\subsection{The present}

At present time, there are many concerns about the static safety of the cathedral, due to the presence of a number of vertical cracks spotted on the pillars of the nave. As a consequence, the Soprintendenza ai Beni Culturali e Ambientali di Siracusa (the agency supervising the preservation of cultural and environmental heritage) commissioned a campaign of diagnostic surveys and numerical modelling to the Politecnico di Milano in order to investigate the state of health of the monument. 

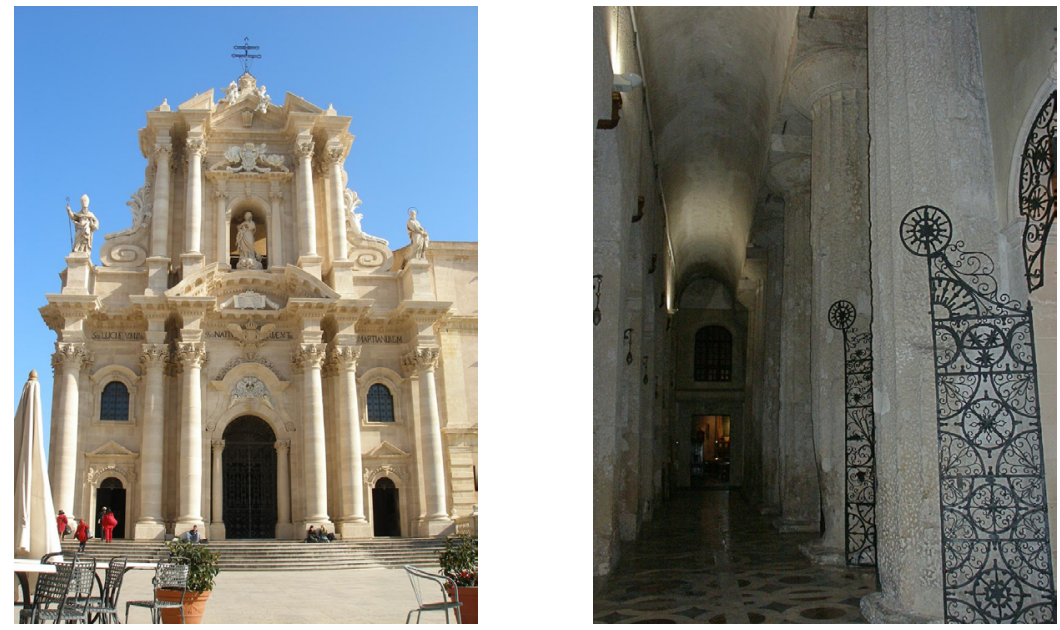

Figure 2: The baroque façade of the cathedral (left) and the ancient Doric columns of the right aisle (right).

Radar, ultrasonic and acoustic emission surveys of the pillars, as well as recording of the time progress of the fractures, together with the numerical modelling, gave evidence that the cracks in the pillars are related with the static compression loads that have a significant increase in the occasion of seismic events. This situation is made worse by the fact that, during the centuries, a number of interventions and restoration works modified the effective cross section of the pillars, since large portions of these elements had been replaced by plastered masonry infills, causing stress concentrations in the remaining limestone blocks [10].

\section{The global 3-D finite element analysis}

\subsection{The finite element model}

The geometric complexity of the monument, as well as the heterogeneity of the materials used in the building, demanded to assemble a 3-D finite element model of the whole cathedral with the aim to investigate its global static and seismic behaviour, and to identify the most critical structural elements. This model was essential in order to calibrate and validate the 2-D mechanistic model.

The 3-D finite element model was assembled by adopting ABAQUS v6.5 finite element code [11]. The model consists of 74521 8-nodes linear brick elements, with a total number of 400374 degrees of freedom. In order to maintain a full control on the distortion of the brick elements, the model was completely implemented "by hand", avoiding the use of automated mesh generation algorithms. Single parts of the cathedral were modelled separately, and then assembled using the tie constraint. The mechanical characteristics of the 

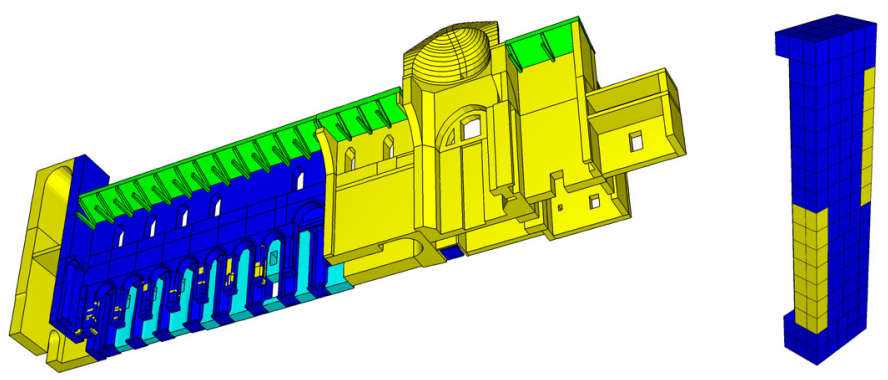

Figure 3: Different materials used in the model (see "color codes" in table 1): on the left a section of the whole model and on the right a detail of a pillar.

Table 1: Mechanical characteristics of the model materials.

\begin{tabular}{|c|c|c|c|c|}
\hline Material & $\mathrm{E}(\mathrm{MPa})$ & Density $\left(\mathrm{kg} / \mathrm{m}^{3}\right)$ & $\nu$ & color code \\
\hline \hline Stone walls and columns & 4500 & 2200 & 0.2 & blue \\
\hline Other walls & 3000 & 2200 & 0.2 & cyan \\
\hline Masonry walls and infills & 2000 & 1800 & 0.2 & yellow \\
\hline Wood and roof & 5000 & 200 & 0.2 & green \\
\hline
\end{tabular}

materials were assigned on the basis of the results of tests carried out on stone samples taken from temple foundations, and on the results of other studies on monuments built with similar local limestone. Cracks and masonry infills in the pillars were modeled by reducing the elastic modulus of single elements according with the results of the diagnostic surveys [10]. The spatial distribution of the different materials is shown in fig. 3 , while the corresponding values for the elastic modulus and mass density are reported in table 1.

\subsection{Eigenvalue analysis and vertical gravity load}

The first step in order to understand the global dynamic behaviour of the building consisted in doing the eigenvalue analysis. The first natural mode essentially involves the façade, as shown in Fig. 4, while the second mode involves the main part of the church, with a deformed shape that is excited by the horizontal accelerations directed along the transversal direction. This mode, which has the greatest participating mass, is the most important in predicting the seismic behaviour of the monument, and it can be well modeled by a simplified 2-D plane model of the transversal section of the nave.

In the case of sole gravity load, mean values for compression stresses were in the range from 0.75 to $1.125 \mathrm{MPa}$; these values are compatible with the working loads for a good quality limestone, nevertheless there were evident stress concentrations in the pillars that had been weakened by the heterogeneities. 

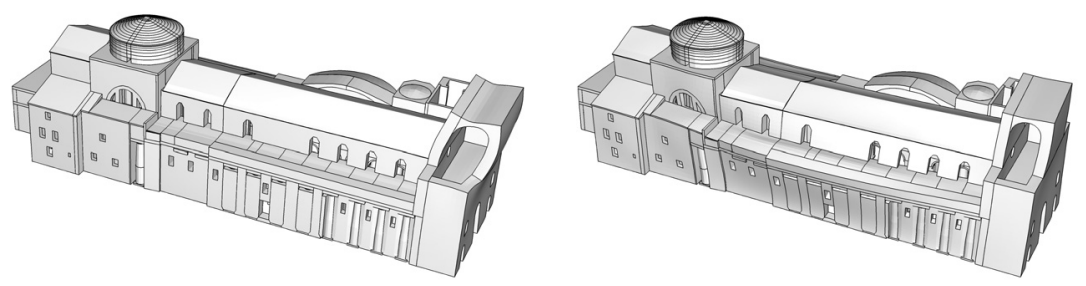

Figure 4: Deformed shapes corresponding to the first (on the left) and the second natural mode of vibration (on the right).
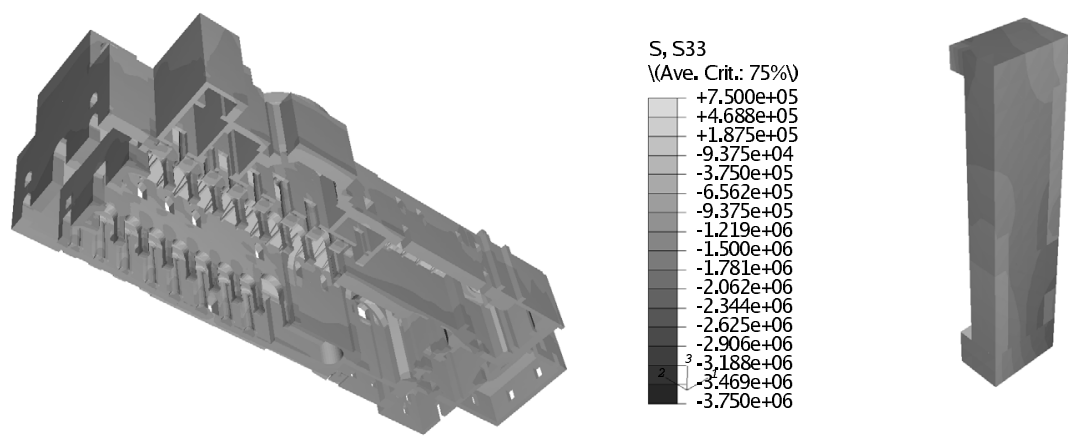

Figure 5: Maps of vertical stress component, $\sigma_{33}$, due to vertical gravity load plus a lateral acceleration of $1.288 \mathrm{~m} / \mathrm{s}^{2}$ along transversal direction $\mathrm{N} \rightarrow \mathrm{S}$.

\subsection{Static horizontal load}

To investigate the global 3-D response to horizontal actions, static analyses were performed with a combination of vertical and lateral gravity-type loads. The value of the applied horizontal acceleration was compatible with the earthquakes with a return period of 140 and 475 years for the site of Syracusae. Lateral loads were applied along the longitudinal and transversal axis in both ways.

An acceleration of $1.288 \mathrm{~m} / \mathrm{s}^{2}$ was adopted with reference to a seismic event with $30 \%$ of probability of occurrence in 50 years. In this case the highest compression stress along the vertical direction reached the value of $1.8 \mathrm{MPa}$ in the nave pillars, as shown in fig. 5. On the other hand, with an acceleration of 3.066 $\mathrm{m} / \mathrm{s}^{2}$ which corresponds to an earthquake with a $10 \%$ of probability of occurrence in 50 years, the maximum compression stress was 2.5 MPa. Moreover, shear stress components reached the value of $0.2 \mathrm{MPa}$ at the base of the northern external wall and in correspondence of the vaults that cover the lateral aisles. The results of the spectral analyses substantially confirmed these data. 

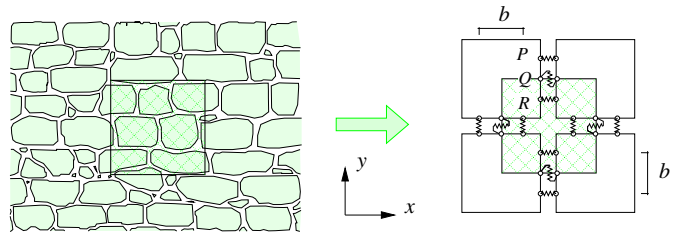

Figure 6: Scheme of a unit cell for macroscale modelling of a representative volume of masonry.

\section{The 2-D model for the transversal section}

\subsection{The rigid element model}

The rigid element model involves the creation of a 2-D plane model of the original structure with simplified geometry and kinematics. The conceptual core of this model is the macroscopic unit cell defined by four quadrilateral rigid elements connected to each other by two normal springs and one shear spring at each side $[6,7]$, as shown in fig. 6 . The cell size should be equal or larger than the minimum representative volume (RVE) of the heterogeneous solid material. In particular, the orthotropy of the shear response and the local mean rotation of the blocks, which depend on the different geometric arrangement of the vertical and horizontal material joints as well as the shape and size of the original blocks, are features that can be accounted at the macro-scale. Out-of the linear elastic field, the main macroscopic constitutive aspects are: the very low tensile strength; the significant post-elastic orthotropy combined with the texture effects; the dependence of the shear strength on vertical compression stress; the progressive mechanical degradation during repeated loading; and the energy dissipation capability. To do this, a simplified heuristic approach is proposed, based on the phenomenological consideration of the main in-plane damage mechanisms that can be described at the meso-scale by adopting specific separate hysteretic laws for the axial and shear deformation between the elements. This separation leads to a large reduction in computational effort, even though a Coulomb-like law, with a coefficient of internal friction equal to 0.2 , is adopted in order to relate the strength of the shear springs to the vertical axial loading. The model of the transversal section was made with a total number of 212 elements and different material characterization and section thickness to each part, as reported in table 2, and as shown in fig. 7.

\subsection{Numerical analyses}

In the case of simple gravity load, the mean values of axial stress at the base of the pillars was $0.9 \mathrm{MPa}$, in good accord with the results from the previous FE model. As expected, the eigenvalue analysis on this model showed for the first model a good correlation with the second, and most significant, vibrating mode of the 3-D model (fig. 4 and 7). 
Table 2: Strength characteristics assigned to the materials.

\begin{tabular}{|l|c|c|c|c|}
\hline Material & $\sigma_{x}^{c} / \sigma_{y}^{c}(\mathrm{MPa})$ & $\sigma_{x}^{t} / \sigma_{y}^{t}(\mathrm{MPa})$ & $\tau_{v}^{m} / \tau_{h}^{m}(\mathrm{MPa})$ & $\tau_{v}^{r} / \tau_{h}^{r}(\mathrm{MPa})$ \\
\hline \hline (1) Stone walls & $2.0 / 2.0$ & $0.2 / 0.2$ & $0.3 / 0.1$ & $0.05 / 0.05$ \\
\hline (2) Other walls & $3.0 / 3.0$ & $0.35 / 0.35$ & $0.075 / 0.075$ & $0.002 / 0.002$ \\
\hline (3) Masonry walls & $7.4 / 7.4$ & $0.74 / 0.74$ & $0.2 / 0.2$ & $0.0075 / 0.0075$ \\
\hline (4) Roof & Elastic & Elastic & Elastic & Elastic \\
\hline
\end{tabular}
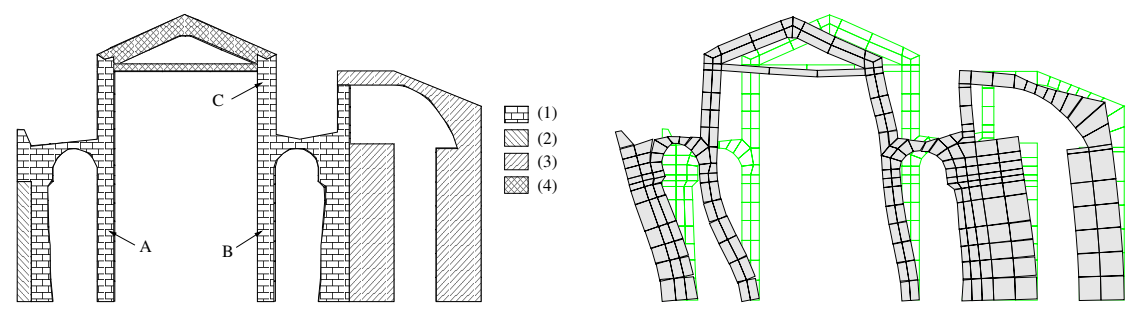

Figure 7: Material characterization of the rigid element model (left - see table 2) and deformed shape of the first mode of vibration (right).

In this paper we present the result of a seismic analysis in which the 2-D model was loaded by three different couples of accelerograms, each-one composed by an horizontal and a vertical time history component. The two artificial accelerograms were compatible with the earthquakes with return period of 140 and 475 years respectively, while the natural couple was composed by the $N S$ and vertical component of acceleration recorded in Colfiorito, Umbria, Italy on 3 September 1997. The time histories of the horizontal component and their elastic spectra at $5 \%$ of damping are shown in fig. 8 .

In order to evaluate the global damaging effects of the seismic actions, it is worth comparing the stress-strain situation under the condition of simple vertical gravity acceleration before and just after the application of the strong ground motion simulation. As an example, the consequences of the application of the Colfiorito recordings are shown in figure 9. After the application of dynamic loads, the shape of the model shows large permanent deformations. Major strain concentrations due to compression are evident at the base of the pillars, while shear damages are present in the upper part of the main aisle corresponding to the Norman raising and on the arch of the right aisle.

\section{Final remarks}

The present integrated procedure allowed to firstly evidentiate the main global kinematics of the building when subjected to seismic actions, afterwards it was possible to calibrate a specific 2-D mechanistic model by which we could perform full dynamical analyses. Results obtained from the sum of these 

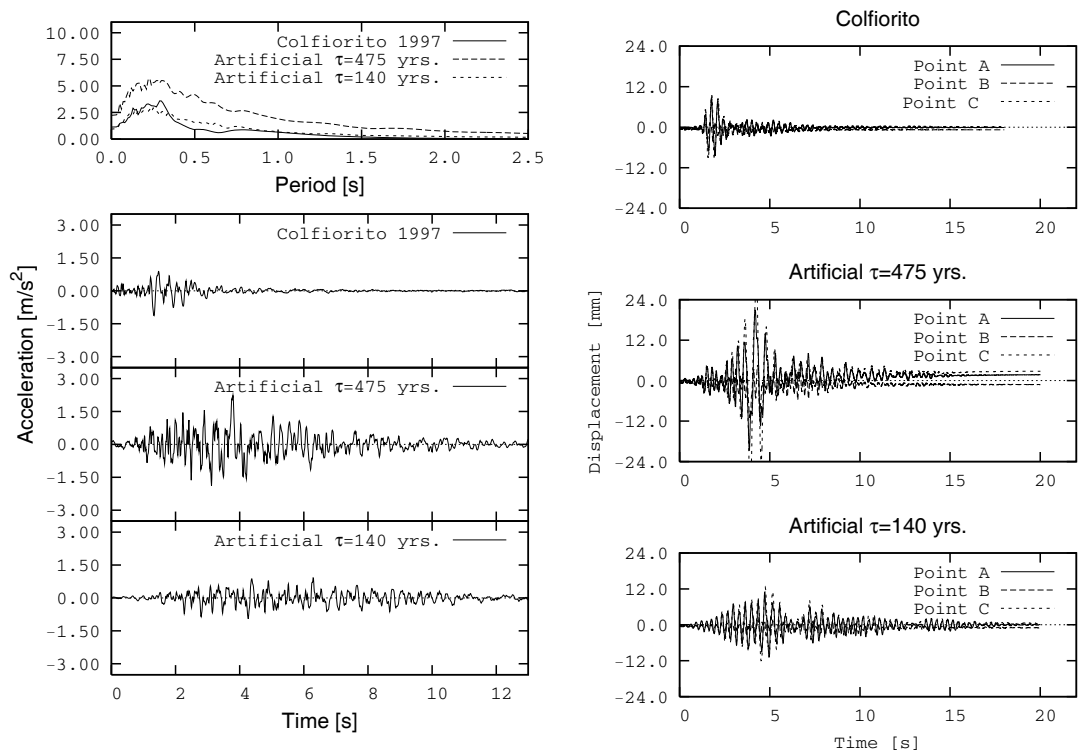

Figure 8: The horizontal component of the three couple of accelerograms used for the dynamic analyses (left), and the displacement time histories response of the three sample points A,B,C (right - see fig.7).
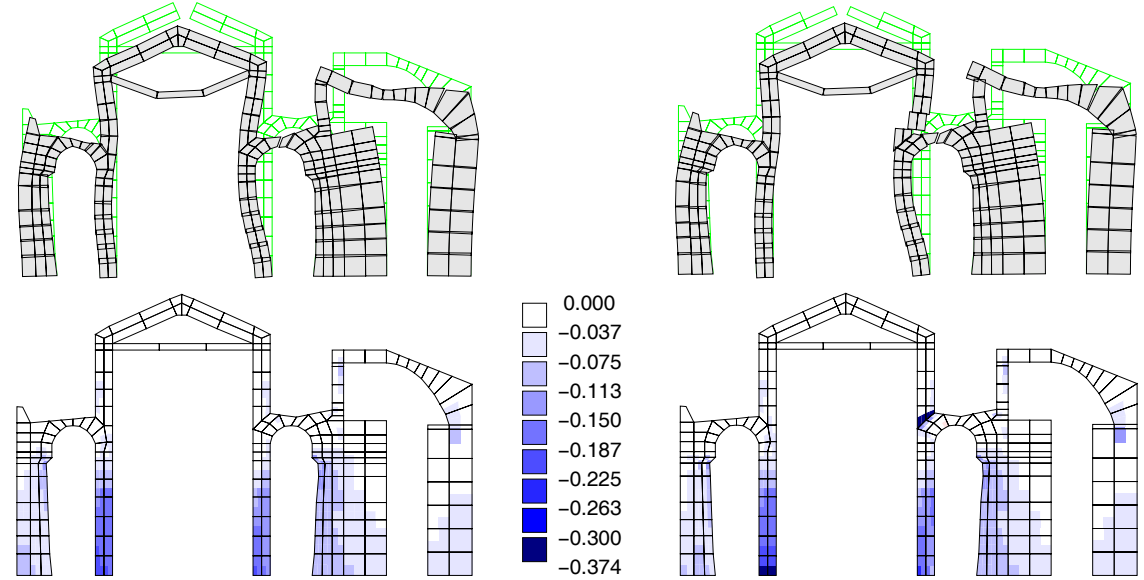

Figure 9: Deformed shape of the model with gravity load before (top-left) and after (top-right) the earthquake of Colfiorito. In the second row, the vertical axial strains are mapped in the same conditions.

analyses revealed some weakness in the building performance that should require further investigations in order to decide about the opportunity of any structural intervention. 


\section{Acknowledgements}

This work was carried out thanks to an agreement between the Politecnico di Milano and the Soprintendenza ai Beni Culturali e Ambientali di Siracusa. The Authors wish to thank, in particular, arch. Mariella Muti and prof. Vincenzo Petrini for their valuable comments and suggestions.

\section{References}

[1] Housner, G., Earthquake Engineering, Prentice-Hall, chapter : Strong ground motion, pp. 75-91, 1970.

[2] Petrini, V. \& Casolo, S., Innovative Approaches to Earthquake Engineering, WIT press, chapter 4: Vulnerability of historical and monumental buildings: significant ground motion parameters and evaluation of the seismic performance, pp. 203-228, 2002.

[3] Doglioni, F., Moretti, A. \& Petrini, V., Le Chiese e il Terremoto. Lint press: Trieste, 1994. In Italian.

[4] Petrini, V., Casolo, S. \& Doglioni, F., Models for vulnerability analysis of monuments and strengthening criteria. Proceedings of the XI European Conference on Earthquake Engineering, Baalkema: Paris, volume of Invited Lectures, pp. 179-198, 1999.

[5] Lourenço, P., Computations on historic masonry structures. Progress in Structural Engineering and Materials, 4(3), pp. 301-319, 2002.

[6] Casolo, S., Modelling in-plane micro-structure of masonry walls by rigid elements. International Journal of Solids and Structures, 13(41), pp. 36253641, 2004.

[7] Casolo, S., Macroscopic modelling of structured materials: relationship between orthotropic cosserat continuum and rigid elements. International Journal of Solids and Structures, 43(3-4), pp. 475-496, 2006.

[8] Boffi, G. \& Casolo, S., Non-linear analyses of masonry arches. Workshop on seismic performance of monuments, Monument-98, Lisbon, pp. 99-108, 1998.

[9] Casolo, S. \& Peña, F., Rigid element model for in-plane dynamics of masonry walls considering hysteretic behaviour and damage. Earthquake Engineering and Structural Dynamics, in press, 2007.

[10] Binda, L., Cantini, L., Condoleo, P., Saisi, A. \& Zanzi, L., Investigation on the pillars of the Syracuse Cathedral in Sicily. 11th International Conference Structural Faults and Repair, Engineering Technical PressEdinburgh: Edinburgh, 2006.

[11] Hibbitt, Karlsson \& Sorensen, Inc., ABAQUS Manuals, version 6.5, 2005. 